\title{
Elastic vascular sclerosis of mesenteric blood vessels in argentaffin carcinoma
}

\author{
P. P. ANTHONY $\mathbf{1}$ AND R. A. B. DRURY
}

From the Bland-Sutton Institute of Pathology, Middlesex Hospital, London, and the Central Middlesex Hospital, London

SYNOPSIS Argentaffin carcinoma (carcinoid tumour) of the ileum has been found to be associated with ischaemic ileal necrosis due to elastic sclerosis of the mesenteric blood vessels. This vascular change was present in 17 out of 25 ileal tumours, all of them invasive, but was absent in 75 appendicular, rectal, and other carcinoids. The pathology is described and essential points of difference are noted from the cardiovascular changes in the carcinoid syndrome. This elastic vascular sclerosis may be due to a product of the tumour and constitute an additional component of the complex range of changes that makes up 'the carcinoid spectrum'.

Necropsy experience with 10 cases of ileal argentaffin carcinoma (carcinoid tumour) revealed four in which ischaemic necrosis of the tumour-bearing segment of intestine had resulted. The mesenteric blood vessels were found to be narrowed by massive proliferation of elastic tissue, mainly in the adventitia. In three cases death was directly attributable to peritonitis caused by this complication. Similar vascular changes were present in a further three cases, two of which showed evidence of impaired blood supply. This observation has prompted a retrospective study of the regional blood vessels in argentaffin carcinoma which confirmed the relatively frequent, though hitherto overlooked, occurrence of this vascular lesion. It was found to be present in ileal tumours only and the implications of this distribution on pathogenesis are discussed.

\section{Material}

Histological material from 100 cases of argentaffin carcinoma was reviewed. Ten of these were necropsy cases and 90 were surgical specimens. All occurred in the 12-year period from 1956 to

'Present address: Makerere University College, P.O. Box 7072, Kampala, Uganda.

Received for publication 29 May 1969.
1968 and were retrieved from the files of the Central Middlesex Hospital, London, the BlandSutton Institute of Pathology, Middlesex Hospital, London, and St Mark's Hospital, London. The 10 necropsy cases were all ileal tumours and had constituted the original series on which the observation of elastic vascular sclerosis was first made. One of these has already been reported as a case of carcinoid heart disease affecting both sides of the heart (Wolfe, Davies, Mathias, and Schachter, 1960). Table I shows the distribution of these 100 cases by site.

Sections were stained with haematoxylin-eosin and, where appropriate, van Gieson's fluid combined with Weigert's or Sheridan's elastic stains. The argentaffin and diazo reactions were available in the majority of cases. Clinical and pathological data were obtained from the case records and the departmental files.

Particular attention was paid to blood vessels both in or near the tumour and away from it,

\begin{tabular}{ll}
\hline Site & Number \\
\hline Appendix & 45 \\
Ileum & $25(1$ in Meckel's diverticulum) \\
Rectum & $25(1$ in pre-sacral teratoma) \\
Ovary & 2 (both in teratomas) \\
Lung & 2 \\
Stomach & 1
\end{tabular}

Table I Distribution of 100 cases of argentaffin carcinoma by site 
these being labelled 'near' and 'distant'. Near blood vessels were present in all cases. Distant, ie, mesenteric blood vessels, were available in 20 out of 25 ileal tumours and in two cases of appendiceal tumours where right hemicolectomy had been carried out. The superior haemorrhoidal vessels were available in five rectal tumours treated by abdomino-perineal resection. Distant vessels were available also in the ovarian and pulmonary tumours. In all, the state of distant blood vessels could be reviewed in 31 cases, 20 of them ileal. Sections of ileum away from the tumour were available in 13 cases. These were stained with Perls' stain for the presence of free iron (Prussian blue reaction).

\section{Results}

Meaningful observations could be made in the appendiceal, ileal, and rectal tumours, the rest being a small number only. The following refers to these three main groups.

AGE WHEN FIRST SEEN

This varied from 14 years (appendix) to 83 years (ileum), the average for the whole series being 53 years. The range in the case of tumours of the appendix was 14 to 58 years (average 29), of the ileum 27 to 83 years (average 62), and of the rectum 24 to 69 years (average 46). There was thus a tendency for tumours of the appendix to occur in young people and those of the ileum in the elderly, whilst those of the rectum presented most frequently in middle age. This distribution agrees with that reported in the world literature (Davies, 1959).

SEX

The overall ratio of males (43) to females (57) was nearly equal: 1 to $1 \cdot 3$. A difference became apparent when the three main groups by site were compared, the ratio then being 1 to $2 \cdot 5$ for tumours of the appendix, 1 to $1 \cdot 11$ for those of the ileum, and 3 to 2 for the rectum. There was thus a tendency for appendiceal tumours to be commoner in females and rectal tumours in males, ileal tumours occurring equally between the sexes. Again, this agrees with data collected from the world literature (Davies, 1959).

\section{CLINICAL PRESENTATION}

\section{Appendix}

Forty of the 45 cases presented with symptoms variously described as typical attacks of appendicitis, 'grumbling' appendix, or appendicular colic. Definite inflammatory changes were found in 12.

\begin{tabular}{llll}
\hline \multirow{2}{*}{ Tumour } & \multicolumn{2}{l}{ Elastic } & Vascular Sclerosis \\
& Present & Absent & \\
\hline Ileum & 17 & 8 & 5 \\
Appendix & - & 45 & - \\
Rectum & - & 25 & - \\
Ovary & - & 2 & - \\
Lung & - & 2 & - \\
Stomach & - & 1 & - \\
\hline
\end{tabular}

Table II Presence of elastic vascular sclerosis by site of tumour and association with intestinal necrosis

\section{Ileum}

Twelve presented with small intestinal obstruction, five with peritonitis due to gangrene of the ileum, two with symptoms and signs of the carcinoid syndrome, one with an inflamed Meckel's diverticulum, and one with intussusception. The tumour was an incidental finding in four.

\section{Rectum}

All cases presented with a variable combination of bleeding, discomfort, and diarrhoea.

\section{HISTOLOGY OF THE TUMOUR}

The histological features of these tumours conformed to the usual patterns. The ileal and appendiceal tumours were of the classical type made up of solid masses and cords of epithelial cells of uniform appearance. The appendiceal tumours were usually both argentaffin and diazo positive, the ileal tumours (some of which were from necropsies and were not fixed fresh) less frequently so. Most of the rectal tumours were of the non-classical, 'atypical' type, forming ribbons, lace-like patterns, and tubules as described by Morson (1962), and with few exceptions were argentaffin and diazo negative. The ileal tumours were the most deeply invasive, but the appendiceal and rectal carcinoids showed local infiltration of the muscle coat. The true nature of all except four had been recognized by their characteristic structure at the time of the first histological report; unexpectedly long survival was the reason leading to review of these four cases and the subsequent diagnosis of argentaffin carcinoma.

\section{PATHOLOGY OF ELASTIC VASCULAR SCLEROSIS}

Small blood vessels in or near the primary tumour ('near' vessels) were always normal, except for a slight condensation of adventitial elastica that was occasionally observed in some cases.

Table II shows the incidence of elastic vascular sclerosis in 'distant' vessels by site of the primary tumour. It was found to be present in and around the mesenteric blood vessels in 17 of the 25 cases of ileal carcinoid tumour, or, if only those tumours where 'distant' vessels were 


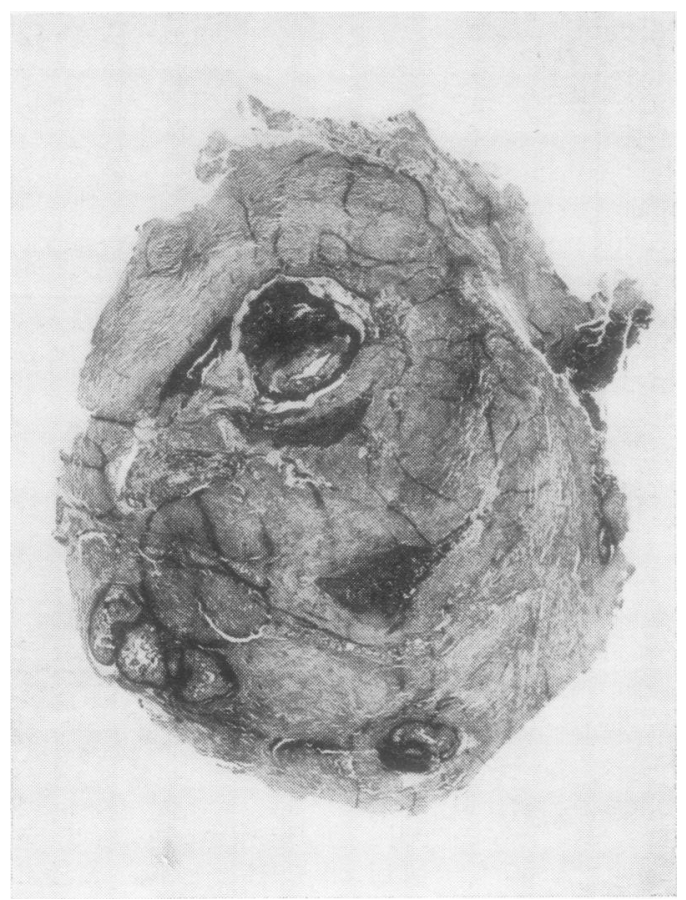

Fig. 1 A mesenteric nodule in which blood vessels show darkly staining elastic thickening of their walls (elastic van Gieson, ×4).

available are considered, in 17 out of 20 cases. Segmental necrosis of the ileum was present in five ileal tumours, in one of which the mesenteric blood vessels were normal. No vascular changes were seen in association with tumours arising at any other site. Macroscopically this elastic vascular sclerosis was hidden in all but one case by mesenteric fibrosis, retraction, and kinking that was associated with local spread of the tumour. In the one case where no such mesenteric distortion had occurred, the tangle of sclerotic vessels stood out in the mesentery as a nodular, hard, partly calcified mass of cartilaginous consistency (Figure 1).

Microscopically a thick mantle of adventitial elastic tissue was found to envelop the involved blood vessels (Figure 2). In a routine haematoxylin eosin preparation this presented as an eosinophilic, glassy, slightly refractile mass that could easily be mistaken for hyalinized collagen (Figure $3)$. In most cases proliferation of similar material was also seen in the intima and in some, a fine, web-like network of fibres obliterated the lumen (Figure 4). The true nature of this lesion was not evident until special stains were applied when it was clearly seen that this accumulation of fibrous tissue was made up of elastica only, collagen being no part of it (Figure 5). Both arteries and veins (Figure 6) appeared involved with their internal elastic laminae remaining quite distinct. Infiltration of surrounding mesenteric soft tissue by argentaffin carcinoma was present in all but the

\begin{tabular}{|c|c|c|c|c|}
\hline \multirow{2}{*}{\multicolumn{2}{|c|}{ Stage of Spread }} & \multicolumn{2}{|c|}{ Elastic V'ascular Sclerosis } & \multirow{2}{*}{$\begin{array}{l}\text { Intestina } \\
\text { Necrosis }\end{array}$} \\
\hline & & Present & Absent & \\
\hline \multirow{3}{*}{$\begin{array}{l}\text { I } \\
\text { II } \\
\text { III }\end{array}$} & $\begin{array}{l}\text { Tumour localized to } \\
\text { bowel wall }\end{array}$ & 0 & 5 & 1 \\
\hline & $\begin{array}{l}\text { Tumour spread to } \\
\text { mesentery and lymph } \\
\text { nodes }\end{array}$ & 7 & 1 & 2 \\
\hline & $\begin{array}{l}\text { Tumour with } \\
\text { mesenteric spread } \\
\text { plus distant } \\
\text { metastases }\end{array}$ & 10 & 2 & 2 \\
\hline \multicolumn{2}{|c|}{ Total } & 17 & 8 & 5 \\
\hline
\end{tabular}

Table III Relationship of elastic vascular sclerosis $\vec{\circ}$ and intestinal necrosis to stage of spread in ileal tumouns

one case already mentioned. Bundles of elastic fibres were often seen in relation to groups of tumour cells (Fig. 7), becoming denser arouthll small arteries, veins, and, apparently, lymphaties (Figure 8). This sclerotic process resulted $\mathrm{dn}$ narrowing of these vessels which appeared to Be the cause of ischaemic necrosis of the related segment of ileum in four patients, of whom throe died as a result of peritonitis. In a fifth patient gangrene of the ileum occurred in association with a carcinoid tumour that did not invade the mesent tery and no vascular changes were found.

RELATIONSHIP OF ELASTIC VASCULAR SCLEROSIS TO STAGE OF TUMOUR SPREADO Table III shows that the presence of this vasculör lesion was clearly related to the stage of advancement of the malignant process. Only ileal tumou $\overrightarrow{\mathrm{fs}}$ have been considered, since blood vessel changes were present in these only. In all 17 cases associated with elastic vascular sclerosis the tumour had spread to the mesentery and/or $\overline{\text { कo }}$ distant sites whereas in five out of eight cases with. out elastic vascular sclerosis the tumour was stall confined to the bowel wall. In four out of the fipe cases associated with small intestinal gangrere, tumour spread was similarly present in both the mesentery and in distant organs. In the fifth case of gangrene with apparently normal blood vesseds there was no tumour spread. It would seem that local spread of the tumour into the mesenteryops almost invariably associated with elastic sclerosis of blood vessels.

PRESENCE OF FREE IRON

Sections of the bowel wall away from tumogr were available in 13 cases of ileal argentafton carcinoma. Four of these showed the presence $\theta f$ free iron in macrophages in and around the bovel wall. Considerable amounts were present in two cases. Patchy haemorrhagic necrosis of the mucosa was seen in one, extending down to the level of the muscularis and was associated with fibrosis of the wall. The other showed submucoms and mesenteric fibrosis. In this latter case rupturie of the anastomosis followed resection of tumour-bearing segment of ileum. 


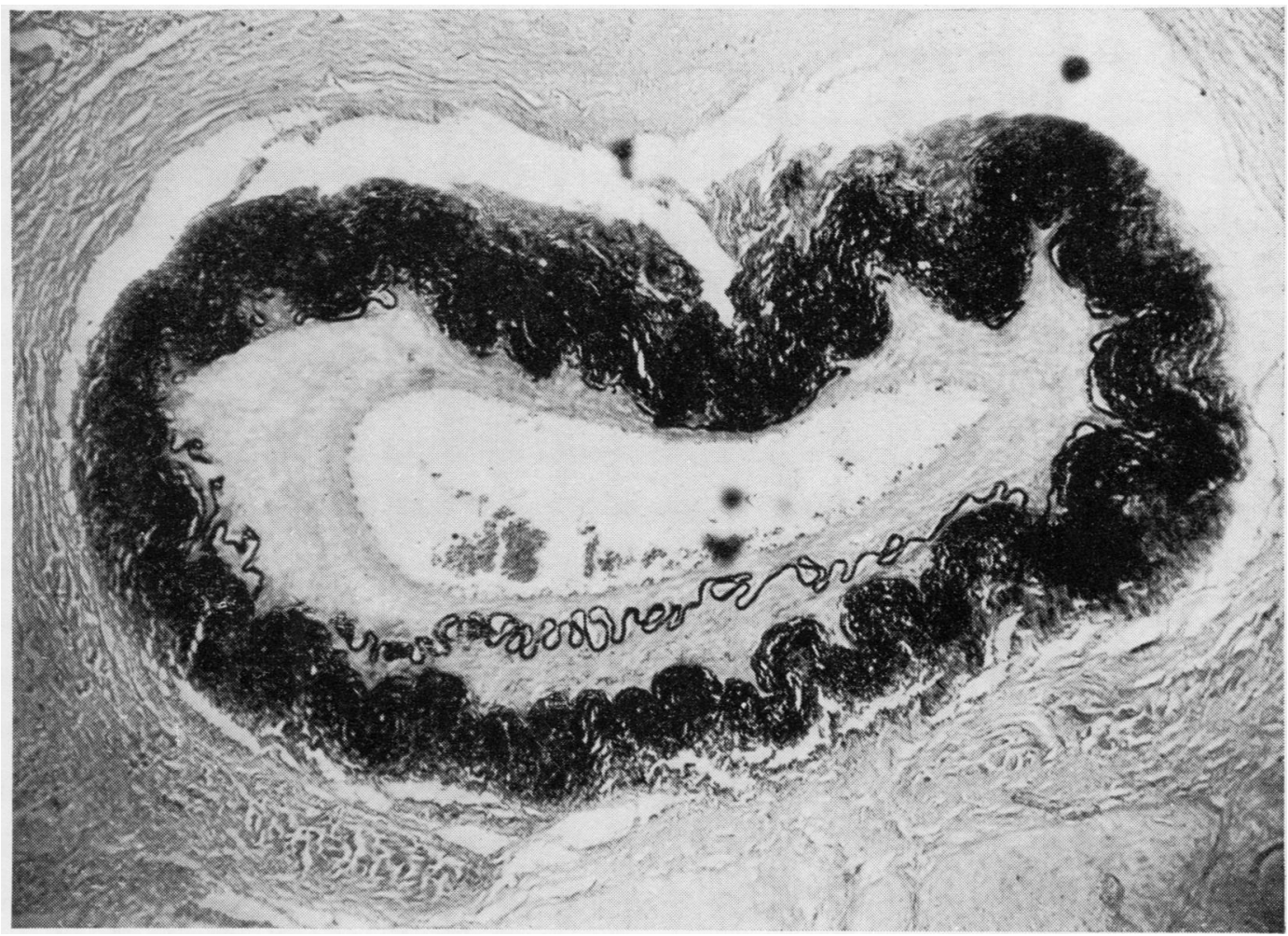

Fig. 2

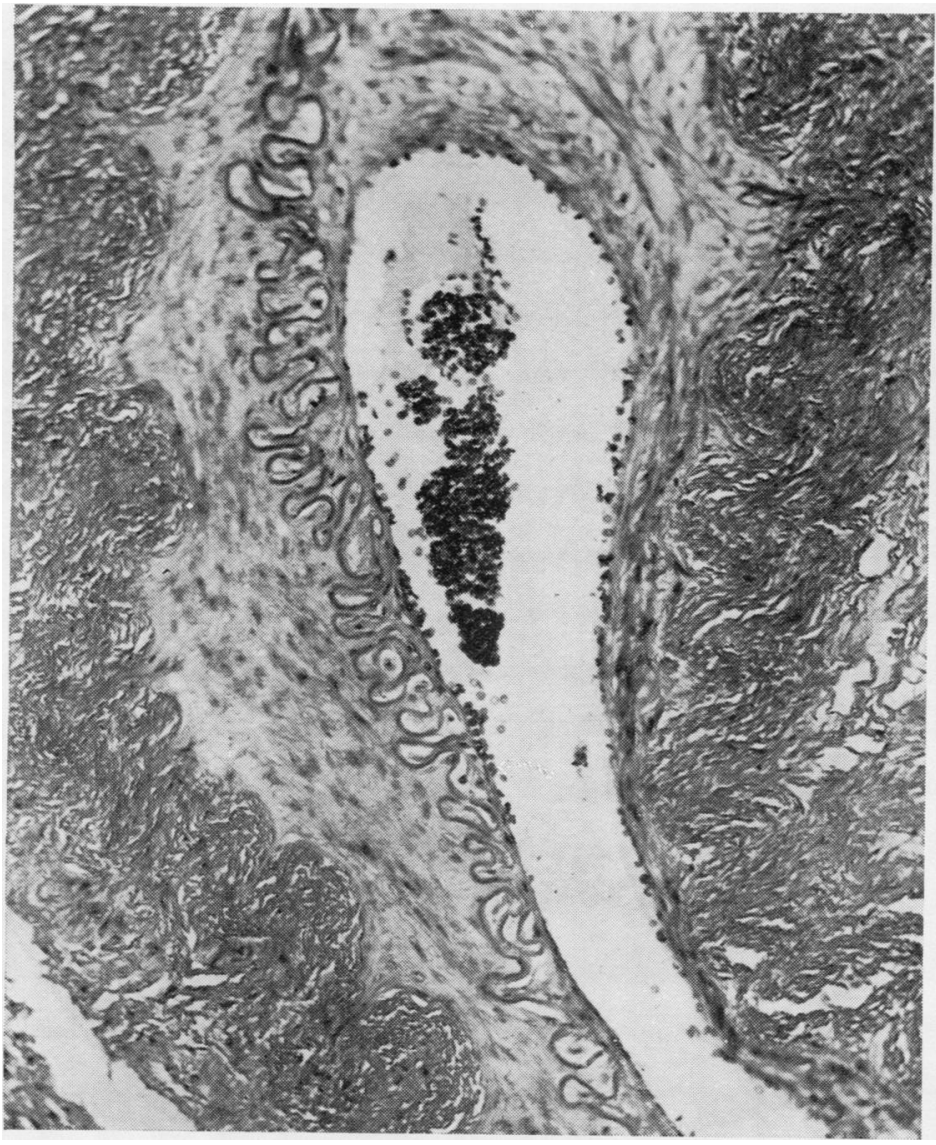

Fig. 2 Mesenteric elastic vascular sclerosis with a thick mantle of adventitial elastic tissue (elastic van Gieson, $\times 50$ ).

Fig. 3 A mesenteric artery surrounded by a thick layer of refractile fibrillary material (haematoxylin and eosin, $\times 120$ ).

Fig. 4 (page 114) A thickened mesenteric artery with a fine, fibrillary obliteration of the lumen at top right (haematoxylin and eosin, $\times 120$ ).

Fig. 5 (page 114) The adventitial accumulation of elastic tissue is clearly shown by special staining (elastic van Gieson, × 120). 


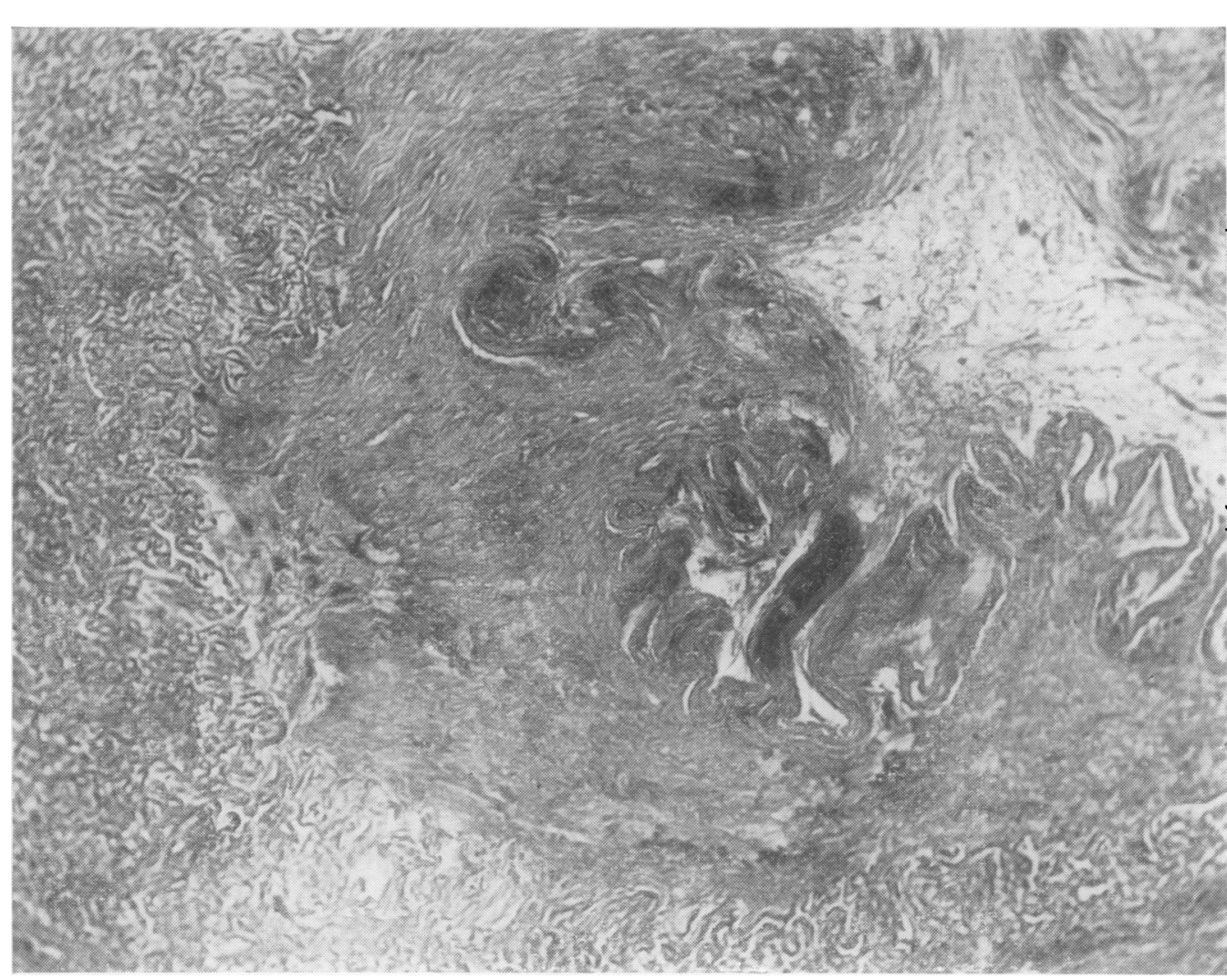

Fig. 4

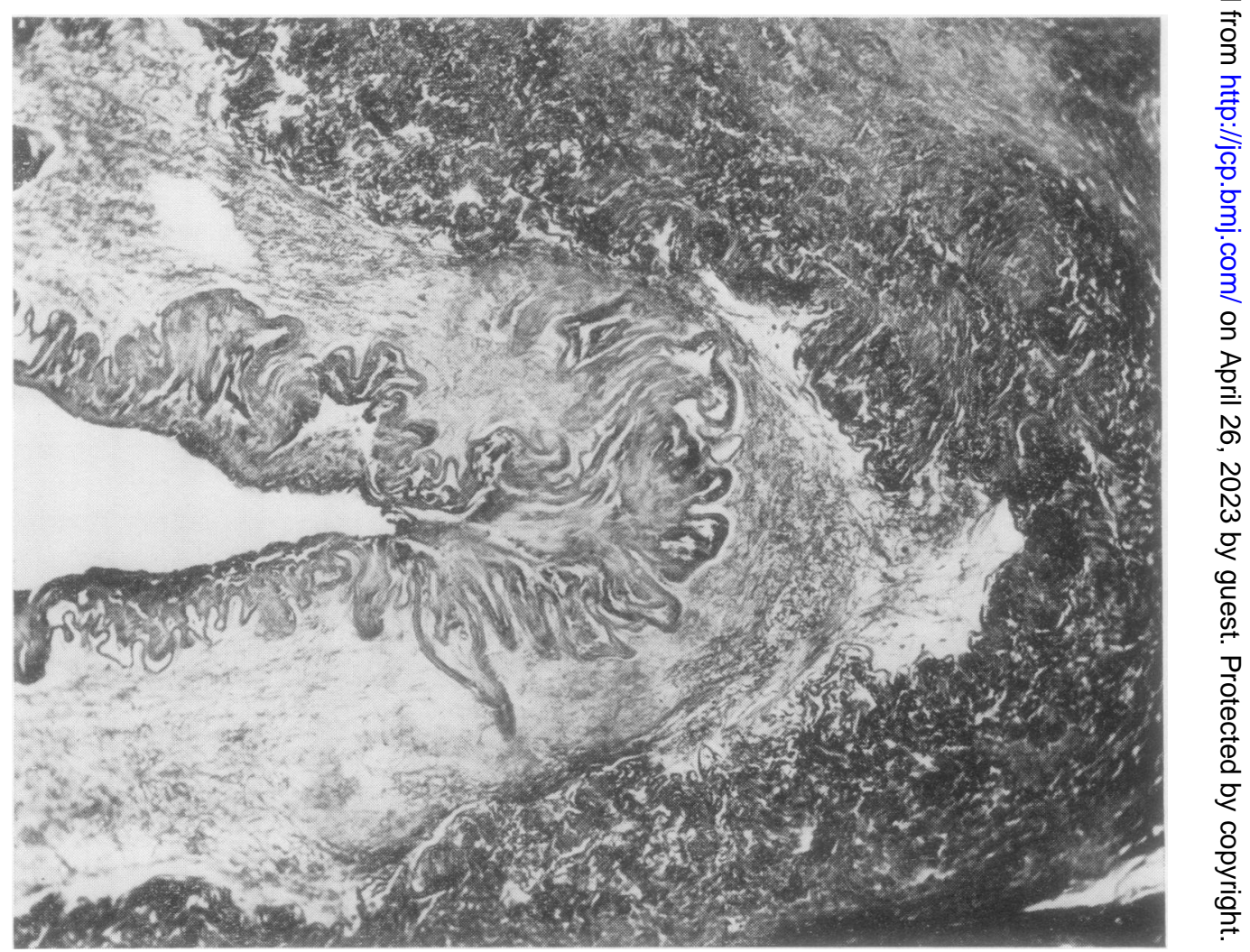

Fig. 5 


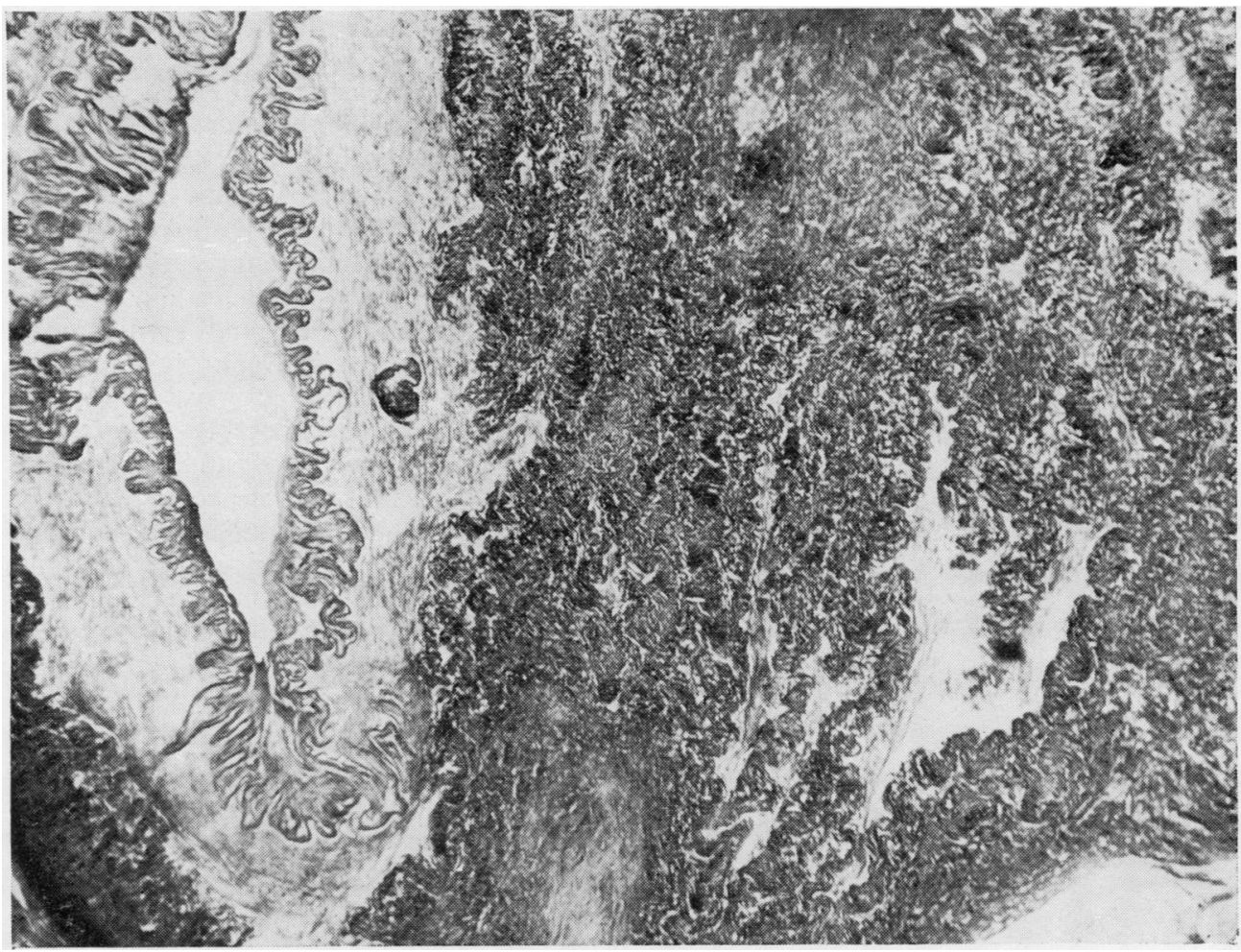

Fig. 6 Elastic vascular sclerosis involving an artery

(left) and vein (right) (elastic van Gieson, $\times 60$ ).

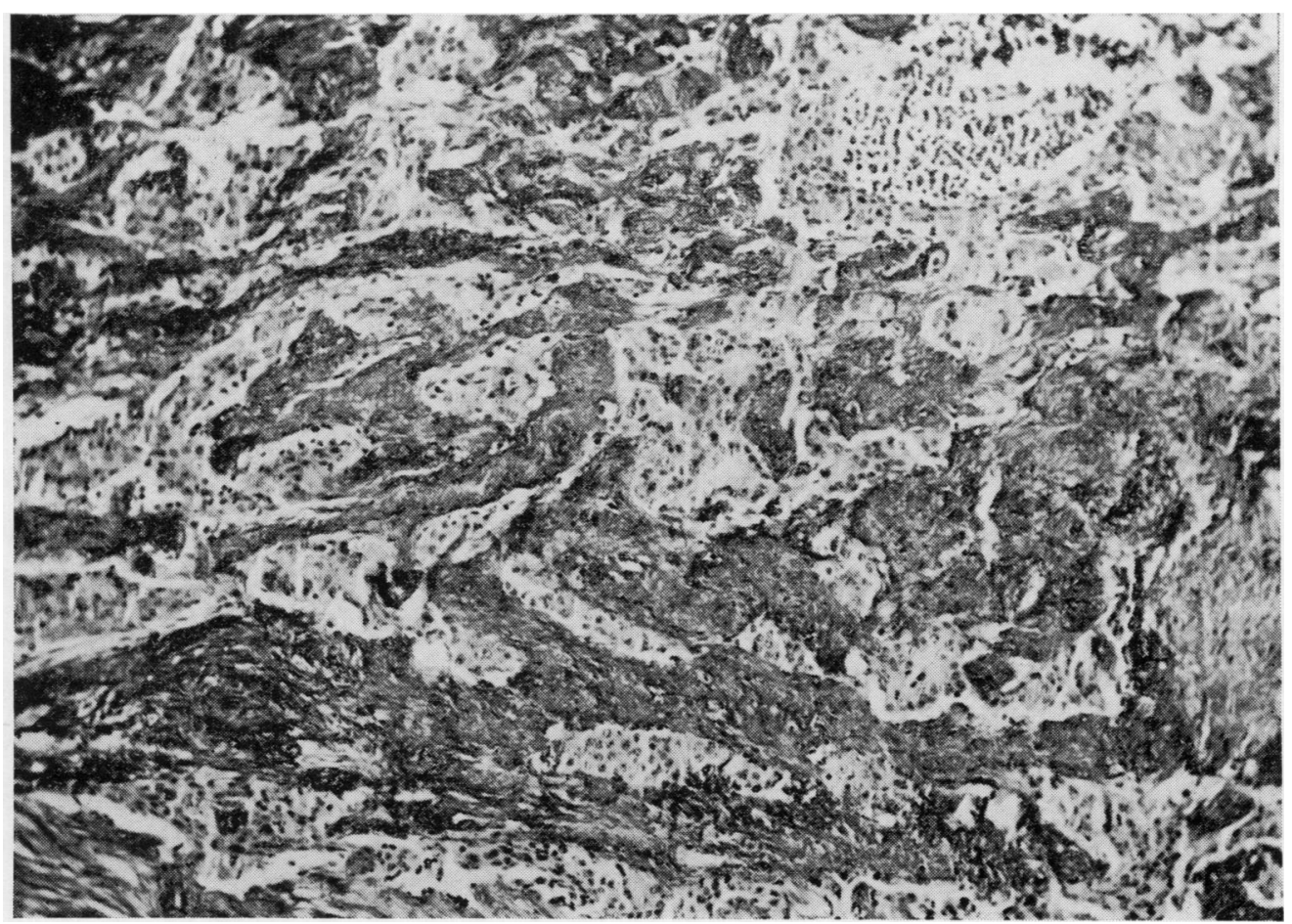

Fig. 7 Darkly staining elastic tissue around islands of tumour cells in the mesentery (elastic van Gieson, $\times 160)$. 


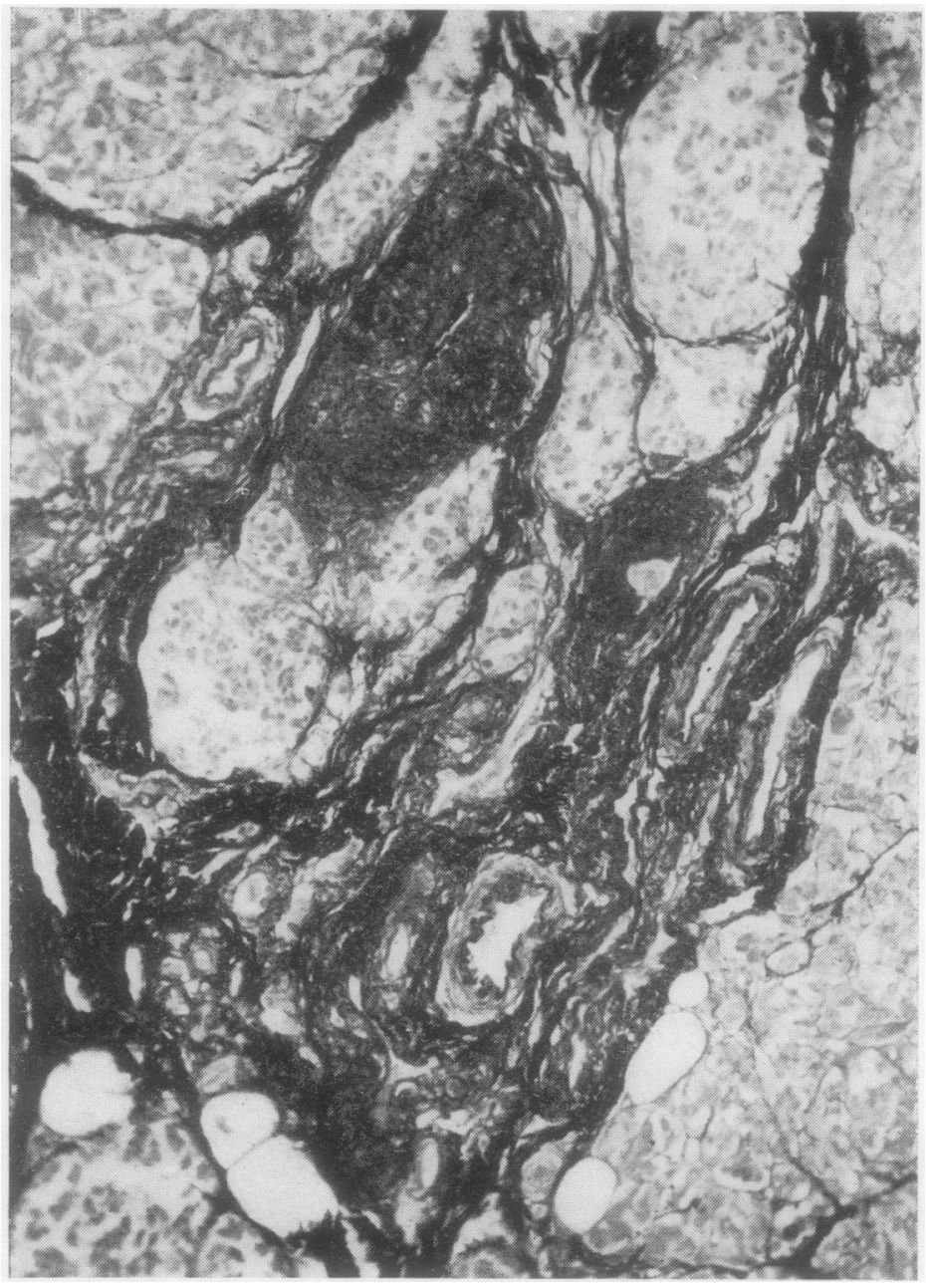

Fig. 8 Local deposition of elastic tissue is particularly marked around small blood vessels and lymphatics in close relationship to islands of tumour cells (elastic van Gieson, $\times 200$ ).

\section{Discussion}

Carcinoid tumours arise from the cells of Kultschitzky in practically any tissue or organ that derives from primitive endoderm. Williams and Sandler (1963) suggested a classification based on anatomical distribution: tumours of lung, stomach, and pancreas being those of foregut, tumours of appendix and ileum of midgut, and tumours of colon and rectum of hindgut origin. This classification is supported by a difference in the pattern of substances that may be secreted by these tumours: foregut carcinoids secrete 5 hydroxytryptophan (5 HTP) and histamine as well as 5 hydroxytryptamine ( 5 HT), midgut carcinoids produce mainly $5 \mathrm{HT}$, and hindgut carcinoids practically never have any secretory activity.
At one time it was thought possible to explain all the manifestations of the carcinoid syndrome in terms of the pharmacology of these substan alone, but this belief has been slowly eroded o recent years. Kinins, notably bradykinin, have come to occupy the star role (Oates, Melmon, Sjoerdsma, Gillespie, and Mason, 1964) though currently efforts are being made to reconcile these differing trends, and a possible synergistic actiōin of $5 \mathrm{HT}$ and bradykinin is being postulated (Lancet, 1968).

The anatomical lesions of the carcinoid syndrome, notably those of the heart, have been extensively studied (Roberts and Sjoerdsmat, 1964). These consist of accumulations of youmg fibrous tissue in the endocardium internal to the elastic lamina that are purely collagenous in nature. Similar changes may be seen in the greạt vessels. Collagenous fibrosis of the mesentery-is frequently present in association with tumours $\overrightarrow{\mathrm{of}}$ the small intestine and causes obstruction By retraction and kinking, a complication known to surgeons for many years (Cooke, 1931; Grim and Bell, 1949; Moertel, Sauer, Dockerty, ağd Baggenstoss, 1961). None of these changes, hotwever, could be related with any consistency $\overrightarrow{c o}$ raised blood or tumour levels of any of the substances referred to above. Neither have attempts been successful at reproducing the cardiac lesion of the carcinoid syndrome in the experimen animal even when injecting $5 \mathrm{HT}$ into rats on doses of $16 \mathrm{mg} / \mathrm{kg}$ up to as long as 353 dags (MacDonald, Robbins, and Mallory, 1958. Fibrosis in the guinea-pig heart has been produced by feeding them a plantain diet rich in $5 \mathrm{HT}$ (McKinney and Crawford, 1965) but the lesiows produced differed from those of the carcinoid syndrome. Kinins are known to alter vascufar permeability (Holdstock, Mathias, and Schachter, 1957) and they may play a part in inducing proliferation of fibrous tissue by allowing plasioa proteins to seep into the tissues of the endecardium, but this remains a theoretical possibiliny only.

No attention has so far been paid to the state blood vessels draining or supplying ileal capcinoid tumours, though the occurrence of ischaemic necrosis of the small intestine has been noted from time to time. Moertel et al (1961) and later Dockerty (1963), in separate reviews of the same series of 209 cases of small intestinal carcinoid tumours seen at the Mayo Clinic over \$0 years, recorded four patients who presented with this complication. This, in the words of the former authors, was due to 'involvement of the superior mesenteric artery in a large mass of mesentefic tumour'. No histology was offered in support $\mathbb{B} f$ this statement. Three of these four died of peritonitis. Kowlessar, Law, and Sleisinger (1959) reported a patient with the malabsorption s. drome associated with metastatic carcinotd tumour who also happened to develop, as case history recorded, small intestinal gangrene 
in the course of this disease. This they ascribed to 'numerous metastatic nodules, one of which caused obstruction to the venous drainage of the compromised bowel'. There was again no histology. Finally, Mallory (1940) noted the presence of sclerotic, calcified nodules in the mesentery associated with metastatic carcinoid tumours which were still present many years after resection of the primary. In view of the known affinity of elastic tissue for calcium, this observation may have been the earliest relating to elastic vascular sclerosis.

This vascular lesion differs in two important respects from those already well known to occur in the carcinoid syndrome. First, it is made up of elastic tissue only, as opposed to the collagenous endocardial deposits in carcinoid heart disease. Secondly, this elastic tissue is laid down mainly in the adventitia of affected vessels, unlike collagenous fibrous tissue that accumulates in the endocardium and the intima of great vessels arising from the heart. Thus both the nature and the distribution of the tissue changes are different.

In any abnormal proliferation of 'elastic tissue' it may be impossible to distinguish between true elastin and elastotic degeneration of collagen. This limitation is recognized, and although Gillman, Penn, Bronks, and Roux (1955) suggested that histological techniques, especially phosphotungstic acid haematoxylin, could help in separating the two, it is not normally possible to do so, even with histochemistry (Mackenzie, Wilson, and Cooke, 1968) or electron microscopy (Tighe, Clarke, and Turvey, 1968).

The clinical significance of this vascular lesion is shown by the occurrence, in four patients, of ischaemic necrosis of the related length of small intestine which resulted in the death of three of them (Anthony, 1970). It is also of interest to note that in a further four cases deposits of free iron were found in the bowel wall away from the tumour, and this was associated with patchy mucosal necrosis and fibrosis extending through the muscularis in at least two cases. In one of these resection was followed by breakdown of the anastomosis. These histological changes are similar to those described in the colon in ischaemic colitis (Marston, Pheils, Thomas, and Morson, 1966), and represent ischaemic ileitis due to elastic vascular sclerosis.

It is suggested that this lesion may be directly attributable to a substance or substances, possibly unrecognized, produced by argentaffin carcinoma. The list of these is constantly growing, prostaglandins having been added recently (Sandler, Karim, and Williams, 1968). The present study of 100 cases of this tumour was largely undertaken with a view to finding circumstantial evidence for this contention. It has been seen that in 31 cases where adequate material was available for the study of blood vessels, both near and away from the tumour, elastic vascular sclerosis was only found in association with ileal carcinoids, which frequently show evidence of secretory activity. Table II shows that vascular changes were present in 17 out of 25 patients, in four of whom ischaemic necrosis of the ileum developed, three dying as a result. The one patient in whom gangrene was apparently associated with normal blood vessels is exceptional. Amongst the 25 cases of ileal carcinoid there were two cases of carcinoid syndrome and evidence of increased secretion of 5 HT was found in a further three, all of which showed vascular lesions. In the remainder no biochemical investigations of tumour secretory activity were done but in five cases symptoms had been present, such as longstanding and apparently unexplained diarrhoea, that might have been due to secretory activity. Further support comes from the fact that vascular changes were not associated with tumours at other sites, namely appendix or rectum, neither of which are known, with very few exceptions, to be capable of secretory activity. It must be added, however, that only in two appendiceal and five rectal tumours were distant blood vessels available for study.

Since both arteries and veins appear to be involved a simple 'downstream' effect cannot be postulated, but it may be noted that proliferation of elastic tissue is present around tumour cells infiltrating the mesentery. This was not a constant feature but suggests that, if this lesion is caused by a substance produced by the tumour, it may well be one that is released locally and carried upwards via the lymphatics, and analysis of lymph might prove rewarding. There was a clear relationship, shown in Table III, between the occurrence of vascular changes and tumour spread to the mesentery, except in the one case already referred to where neither was present though gangrene of the tumour-bearing segment of ileum did result. This one case brings to mind the fact that $5 \mathrm{HT}$ is known to be a powerful constrictor of large arteries and veins (Haddy, 1960).

Two further possibilities regarding pathogenesis may be considered. One, that this elastic tissue proliferation is only an apparent one, being due to condensation of elastic fibres normally present in the adventitia of large vessels, such as those of the mesentery. Retraction associated with fibrosis of the latter would then produce a concertina-like effect, giving the impression of an increase in amount. In one case no such retraction was present, yet there was a massive increase in elastica. Also, in other conditions associated with such retraction of the mesentery, such as retractile mesenteritis (Tedeschi and Botta, 1962), visceral Weber-Christian disease, and retroperitoneal fibrosis, no such effect has been described. Second, that this lesion is due to the effect of slowly growing tumours in general. Endarteritis obliterans may certainly be seen in association with such tumours but this is entirely different from the lesion described here.

It can be concluded that, although elastic 
vascular sclerosis cannot at present be explained in terms of the known secretory activity of carcinoid tumours, it is nevertheless likely to be related to it and that it may, therefore, be added as a new feature to the already complex range that makes up 'the carcinoid spectrum'.

We wish to thank Professor A. C. Thackray and Dr B. C. Morson for making material available for study, and Dr D. G. Grahame-Smith for helpful advice.

\section{References}

Anthony, P. P. (1970). Gangrene of small intestine - a complication of angentaffin carcinoma. Br. J. Surg., 57, 118-122.

Cooke, H. H. (1931). Carcinoid tumours of the small intestine. Arch. Surg., 22, 568-597.

Davies, A. J. (1959). Carcinoid tumours (Argentaffinomata). Ann. roy. Coll. Surg. Engl., 25, 277-297.

Dockerty, M. B. (1963). Carcinoid tumours. Calif. Med., 99, $157-160$.

Gillman, T., Penn, J., Bronks, D., and Roux, M. (1955). Abnormal elastic fibers. Arch. Path., 59, 733.

Grimes, O. F., and Bell, H. G. (1949). Carcinoid tumours of the intestine. Surg. Gynec. Obstet., 88, 317-325.

Haddy, F. H. (1960). Serotonin and the vascular system. Angiology, 11, 21-24.

Holdstock, D. J., Mathias, A. P., and Schachter, M. (1957). A comparative study of kinin, kallidin and bradykinin. Brit. J. Pharmacol., 12, 149-158.

Kowlessar, O. D., Law, D. H., and Sleisinger, M. H. (1959). Malabsorption syndrome associated with metastatic carcinoid tumor. Amer. J. Med., 27, 673-677.

Lancet (Leading article) (1968). Pharmacology of the carcinoid syndrome. Lancet, 1, 404-405.
MacDonald, R. A., Robbins, S. L., and Mallory, G. K. (1958) Morphologic effects of serotonin. Arch. Path., 65, 369-37):

Mackenzie, D. H., Wilson, J. F., and Cooke, K. B. (1968). Elasto fibroma. J. clin. Path., 21, 470-475.

McKinney, B., and Crawford, M. A. (1965). Fibrosis in guine蚂 pig heart produced by plantain diet. Lancet, 2, 880-882.0

Mallory, T. B. (1940). Discussion of case record, Massachusetts General Hospital. New Engl. J. Med., 222, 684.

Marston, A., Pheils, M. T., Thomas, M. L., and Morson, B. (1966). Ischaemic colitis. Gut, 7, 1-15.

Moertel, C. G., Sauer, W. G., Dockerty, M. B., and Baggensto A. H. (1961). Life history of the carcinoid tumor of the small intestine. Cancer (Philad.), 14, 901-912.

Morson, B. C. (1962). Pathology of carcinoid tumours. In Mod Trends in Gastro-enterology, 2nd series, edited by F. Avery Jones, pp. 107-117. Butterworth, London.

Oates, J. A., Melmon, K., Sjoerdsma, A., Gillespie, L., and Mason D. T. (1964). Release of a kinin peptide in the carcined syndrome. Lancet, 1, 514-517.

Roberts, W. C., and Sjoerdsma, A. (1964). The cardiac diseaste associated with carcinoid syndrome (Carcinoid hegt disease). Amer. J. Med., 36, 5-34.

Sandler, M., Karim, S. M. M., and Williams, E. D. (1968). Pros glandins in amino-peptide-secreting tumours. Lancet, 3 1053-1054.

Tedeschi, C. G., and Botta, G. C. (1962). Retractive mesenteritis New Engl. J. Med., 266, 1035-1040.

Tighe, J. R., Clarke, A. E., and Turvey, D. J. (1968). Elastofibrom dorsi. J. clin. Path., 21, 463-469.

Williams, E. D., and Sandler, M. (1963). The classification $Q_{f}$ carcinoid tumours. Lancet, 1, 238-239.

Wolfe, H. R. I., Davies, A., Mathias, A. P., and Schachter, M. (1960). Metastatic argentaffinoma secreting 5-hydro tryptamine in a patient with a patent foramen ovale. $B$ Med. J., 1, 925-929. 